\title{
APPLY: A prospective observational study of clinical practice patterns of darbepoetin alfa use in patients with chemotherapy-induced anemia in Romania
}

\author{
Nicoleta Mariana Berbec - Dana Lucia Stanculeanu • Nicoleta Sorina Badelita - Mariana Vasilica • \\ Dorel Ionel Popovici · Andrei Colita · Cristina Neacsu · Alexandru Iordan
}

Received: 13 October 2017 / Accepted: 6 February 2018 / Published online: 2 March 2018

(C) The Author(s) 2018. This article is an open access publication.

\begin{abstract}
Summary
Purpose The primary objective of this study was to evaluate the compliance of Romanian physicians with the national therapeutic protocol and international guidelines on treatment with erythropoiesis-stimulating agents in anemic cancer patients receiving chemotherapy. The secondary objective was to assess the hemoglobin $(\mathrm{Hb})$ level change due to anemia treatment and safety of darbepoetin alfa.

Methods This was a single-arm, prospective, longitudinal, multicenter, observational study in patients with nonmyeloid malignancies and symptomatic chemotherapy-induced anemia treated concomitantly with darbepoetin alfa. Patients were followed
\end{abstract}

\begin{abstract}
Author contribution statement According to the definition given by the International Committee of Medical Journal Editors (ICMJE), all authors listed above qualify for authorship based on making one or more of the substantial contributions to the intellectual content of: (i) Conception and design; (ii) Analysis and interpretation of data; (iii) Participation in drafting of the manuscript; (iv) Critical revision of the manuscript for important intellectual content. Nicoleta Mariana Berbec and Dana Lucia Stanculeanu contributed equally to the manuscript.
\end{abstract}

Electronic supplementary material The online version of this article (https://doi.org/10.1007/s12254-018-0390-4) contains supplementary material, which is available to authorized users.

\section{N. M. Berbec $(\bowtie) \cdot$ A. Colita}

Colea Clinical Hospital, 1 Ion C. Brătianu Bd, Bucharest, Romania

nicole_olt@yahoo.com

A. Colita
andreicolita@yahoo.com

D. L. Stanculeanu

Institute of Oncology “Prof. Dr. Al Trestioreanu”, 252

Fundeni Rd, 2nd District, Bucharest, Romania

dlstanculeanu@gmail.com for the duration of chemotherapy, but no shorter than three and no longer than eight cycles, irrespective of their exposure to darbepoetin alfa.

Results In this study, 497 patients with a mean age of 60.6 years were analyzed. Most patients $(80.7 \%)$ were initiated on darbepoetin alfa at a $\mathrm{Hb}$ of $9-11 \mathrm{~g} / \mathrm{dL}$, congruent with recommendations. The median $\mathrm{Hb}$ increased by $0.9 \mathrm{~g} / \mathrm{dL}$ between baseline and week 12 . $\mathrm{Hb}$ target achievement was higher among patients treated according to guidelines than those initiated at $\mathrm{Hb}<9 \mathrm{~g} / \mathrm{dL}$. A similar trend was observed for red blood cell transfusion requirements. No new safety signals were reported for darbepoetin alfa.

\section{N. S. Badelita $\cdot$ M. Vasilica}

Fundeni Clinical Institute, 258 Fundeni Rd., Bucharest, Romania

\section{N. S. Badelita}

sorinabadelita@gmail.com

M. Vasilica

v.madalina@yahoo.com

D. I. Popovici

OncoHelp Clinic, 59 Ciprian Porumbescu St., Timisoara,

Romania

dipopovici@yahoo.com

C. Neacsu $\cdot$ A. Iordan

Amgen Romania, 1A Bucuresti-Ploiesti Rd., 1st District, Bucharest, Romania

\section{Neacsu}

cneascu@amgen.com

\section{A. Iordan}

aiordan@amgen.com 
Conclusions The majority of patients were treated according to national and international recommendations. Guideline adherence was associated with more frequent achievement of $\mathrm{Hb}$ targets and lower red blood cell transfusion requirements compared with patients starting anemia treatment with darbepoetin alfa at lower-than-recommended $\mathrm{Hb}$ levels.

Keywords Darbepoetin alfa · Chemotherapy-induced anemia - Hemoglobin · Fatigue - EORTC guidelines · Romanian National Therapeutic Protocol on ESA prescription

\section{Introduction}

Chemotherapy-induced anemia, a common complication of myelotoxic chemotherapy [1, 2], is associated with clinical symptoms such as fatigue, which seriously compromises patients' quality of life [3]. Guidelines commonly recommend the administration of erythropoiesis-stimulating agents (ESAs) to improve patients' quality of life and to avoid severe, life-threatening anemia, which can only be alleviated with the help of allogeneic red blood cell transfusions (RBCTs) [4, 5]. Darbepoetin alfa, a long-acting ESA, is authorized to be administered subcutaneously to patients with symptomatic chemotherapy-induced anemia (hemoglobin [Hb] concentration $\leq 10 \mathrm{~g} / \mathrm{dL}$ ) at a recommended initial dose of $500 \mu \mathrm{g}(6.75 \mu \mathrm{g} / \mathrm{kg})$ given once every three weeks. Once weekly dosing can be given at $2.25 \mu \mathrm{g} / \mathrm{kg}$ body weight. If the clinical response of the patient (fatigue, $\mathrm{Hb}$ response) is inadequate after 9 weeks, further therapy may not be effective. In the European Medicines Agency (EMA) Summary of Product Characteristics (SmPC), Hb concentrations should not exceed $12 \mathrm{~g} / \mathrm{dL}$, although due to intrapatient variability, occasional individual $\mathrm{Hb}$ values for a patient above and below the desired level may be observed and the darbepoetin alfa dose should be managed so that a $\mathrm{Hb}$ target range of $10-12 \mathrm{~g} / \mathrm{dL}$ is maintained [6].

In accordance with international guidelines, the goal of anemia treatment as per the Romanian National Therapeutic Protocol on ESA prescription is to reduce the requirement for allogeneic RBCTs and maintain quality of life in patients receiving chemotherapy [7]. According to the Romanian National Therapeutic Protocol on ESA prescription at the time of study design, a $\mathrm{Hb}$ concentration of 9-11 g/dL was recommended for the initiation of ESA therapy. In 2013, the local prescription protocol in Bucharest changed and allowed initiation of ESAs only in patients with a $\mathrm{Hb}$ in the range of $8-10 \mathrm{~g} / \mathrm{dL}$, drawing on European Society of Medical Oncology (ESMO) recommendations with a cut-off $\mathrm{Hb}$ of $\leq 10 \mathrm{~g} / \mathrm{dL}$ for ESA initiation [5]. However, there are no data available on how well these instructions are followed and implemented in routine clinical practice in Romania. Therefore, the aim of this long-term prospective study was to assess how treatment standards for chemotherapy-induced anemia have evolved over time in Romania, to describe how effectively patients with chemotherapy-induced anemia are treated with darbepoetin alfa, and to examine adherence to authority recommendations and product labeling.

\section{Methods}

\section{Study design}

This was a single-arm, longitudinal, multicenter observational (noninterventional) study, prospectively collecting data from patients with nonmyeloid malignancies suffering from symptomatic chemotherapyinduced anemia, who were treated with darbepoetin alfa. Patients were treated and observed over a favorable minimum of 3 and a maximum of 8 chemotherapy cycles.

Patient data were taken from the medical files and registered in an electronic web-based documentation form. Data were collected at enrollment and during chemotherapy treatment for up to 4 weeks after the latest dose of darbepoetin alfa. In case chemotherapy was discontinued, darbepoetin alfa was discontinued approximately 4 weeks after the end of chemotherapy (as per SmPC) and patient data were collected up to 4 weeks after the last dose of darbepoetin alfa.

This noninterventional study did not alter the routine clinical management of the participating patients and no laboratory or diagnostic tests, other than those performed as part of the patient's routine medical care, were required.

\section{Study objectives and endpoints}

The primary study objective was to evaluate the compliance with the local Romanian national therapeutic protocol and with European Organization for Research and Treatment of Cancer (EORTC) guidelines on ESA treatment. The primary endpoint was to estimate the proportion of patients within the $\mathrm{Hb}$ range of 9-11 g/dL at initiation of darbepoetin alfa.

Secondary objectives included the assessment of $\mathrm{Hb}$ level change over time and the safety of darbepoetin alfa. Secondary endpoints were the proportion of darbepoetin alfa-treated patients achieving a $\mathrm{Hb}$ concentration $>11.0 \mathrm{~g} / \mathrm{dL}$ during the study at weeks 6 , 9, and 12; the median increase in $\mathrm{Hb}$ from initiation of darbepoetin alfa to week 6, 9, 12 and the last observed $\mathrm{Hb}$ level; the proportion of darbepoetin alfa treated patients (with a $\mathrm{Hb}<10.0 \mathrm{~g} / \mathrm{dL}$ at darbepoetin alfa initiation) achieving a $\mathrm{Hb}$ concentration $\geq 10.0 \mathrm{~g} / \mathrm{dL}$ during the study at weeks 6,9 , and 12; the time to and the mean $\mathrm{Hb}$ concentration after achieving first time $\mathrm{Hb}$ level $\geq 10.0 \mathrm{~g} / \mathrm{dL}$ after darbepoetin alfa initiation; the proportion of achieved $\mathrm{Hb}$ levels at weeks 6, 9, 12, and the last observed $\mathrm{Hb}$ level compared to baseline $\mathrm{Hb}$ levels; the proportion of patients treated with darbe- 
poetin alfa with at least one RBCT or full blood transfusion during the study; the RBCT or full blood transfusion requirements per baseline $\mathrm{Hb}$ initiated during the treatment period with darbepoetin alfa $500 \mu \mathrm{g}$ once every 3 weeks (Q3W; estimation of the number of transfusions per patient, transfusion rates by both crude rate and Kaplan-Meier method, as well as number of transfusion units administered during the treatment period); cumulative dose and duration of dosing of darbepoetin alfa; and a summary of darbepoetin alfa treated patients receiving computed tomography (CT) at Full Dose on Schedule (FDOS). A cycle was considered to be full dose on schedule if percent of dose reduction (DR) of any myelotoxic drug did not exceed $10 \%$ of planned amount and dose delay from planned date (if any) did not exceed 3 days. Adverse drug reactions (ADRs) to darbepoetin alfa were also collected.

\section{Eligibility criteria}

Patients with a diagnosis of solid or hematological tumors (nonmyeloid malignancies), regardless of their disease status, who received chemotherapy and experienced chemotherapy-induced anemia with one or more symptoms of fatigue and who received at least one dose of darbepoetin alfa before enrollment were included. Darbepoetin alfa needed to be administered in accordance with the version of the SmPC valid at the time of study conduct. Patients had to have a life expectancy of at least 4 months and had to sign an informed consent form.

Patients were excluded if they had any contraindication for treatment with darbepoetin alfa as per SmPC or if they concurrently participated in any other clinical trial, were administered any ESA therapy other than darbepoetin alfa or had received RBCTs or fullblood transfusion up to 28 days prior to enrollment, or had planned radiotherapy during treatment with darbepoetin alfa.

\section{Statistical analysis}

A formal hypothesis was not tested. Statistical analyses were descriptive in nature. For continuous variables, the mean, standard deviation (SD), median, first and third quartiles (interquartile range, IQR), minimum and maximum values were presented along with $95 \%$ two-sided confidence intervals (CIs), where appropriate. Missing values of continuous variables were counted as "missing". However, to assess $\mathrm{Hb}$ level at week 6 , week 9, and week 12 last observation carried forward (LOCF) rule or closest value imputation rule was applied. For categorical variables, the number and percentage of patients in each category were reported. Missing values for categorical variables were excluded from the calculation of CIs, but the number and percentage of patients with missing results were provided. For binary variables, the num- ber and percentage of patients were reported, along with exact two-sided CIs, where appropriate.

The analysis of all predefined variables, including safety, was performed on the full analysis set (FAS). The FAS consisted of all patients who met the eligibility criteria and received at least one dose of darbepoetin alfa. Analyses were repeated for the per-protocol analysis set, defined as all patients who met the eligibility criteria, received darbepoetin alfa for symptomatic chemotherapy-induced anemia, and completed a minimum of 3 and up to a maximum of 8 cycles of chemotherapy, irrespective of the length of their exposure to darbepoetin alfa.

To determine the sample size necessary to assess the proportion of patients with $\mathrm{Hb}$ concentrations within the range $9-11 \mathrm{~g} / \mathrm{dL}$ at initiation of darbepoetin alfa, previous observation studies were taken as a basis. Previous studies showed a proportion of patients with $\mathrm{Hb}$ concentrations in the range of $9-11 \mathrm{~g} / \mathrm{dL}$ at enrollment of about $64 \%$. A sample size of 500 patients was found to ensure that the halfwidth of the $95 \%$ CI for the proportion of patients with $\mathrm{Hb}$ at enrollment in the range of $9-11 \mathrm{~g} / \mathrm{dL}$ would be no larger than 4.4 percentage points (p.p.). The calculated sample size also allowed getting results with sufficient precision in all other endpoints.

Following the change in the Romanian protocol to use ESAs according to current label, a supplemental statistical analysis plan was designed to further assess the adherence to the current darbepoetin alfa label as well as to assess the efficacy results if darbepoetin alfa was used in patients with $\mathrm{Hb}$ levels of 8-10 g/dL. Post hoc the data were also assessed separately for patients with solid tumors and hematological malignancies.

\section{Results}

The study was conducted between December 2011 and February 2015 in 35 Romanian centers, with a total study duration of 38 months. The FAS comprised 497 eligible patients; 22 patients were excluded from

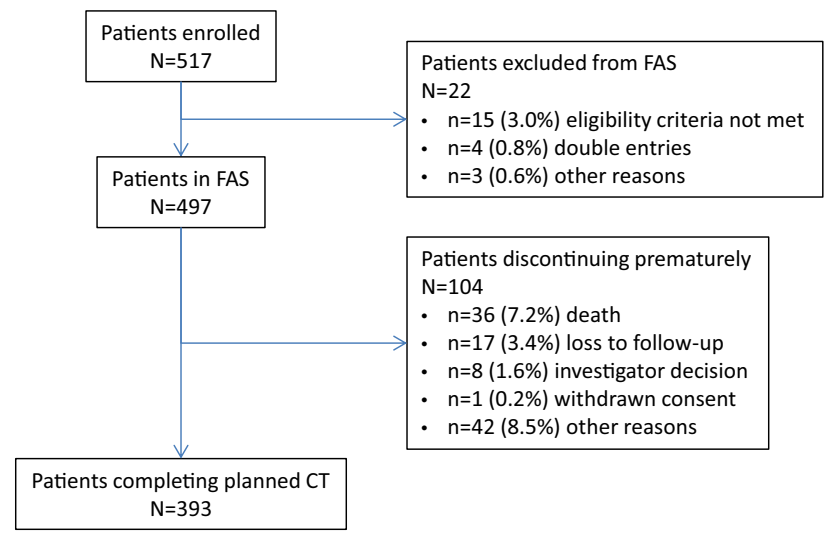

Fig. 1 Patient disposition. Percentages are based on the number of patients in the FAS. CT chemotherapy, FAS full analysis set 
statistical analysis. Of the patients included in the FAS, 393 (79.1\%) completed 3-8 chemotherapy cycles as planned; 104 patients $(20.9 \%)$ discontinued (Fig. 1 ). The median (IQR) duration of observation was 4.0 $(3.0,5.0)$ cycles and $107.0(80.0,140.0)$ days.

Patient mean (SD) age was 60.6 (10.67) years and all patients were of Caucasian ethnicity. The vast majority of patients $(n=483 ; 97.2 \%)$ had an Eastern Cooperative Oncology Group (ECOG) performance status of $0-2$. Patients had a variety of solid or hematological cancers. The median (IQR) time since diagnosis was 107.0 (62.0, 278.0) days. The majority of patients had no comorbidities prior to enrollment and had received no prior anticancer therapies or radiotherapy

Table 1 Patient demographics and baseline characteristics

\begin{tabular}{|c|c|}
\hline Characteristics & $N=497$ \\
\hline \multicolumn{2}{|l|}{ Age } \\
\hline Mean (SD), years & $60.6(10.67)$ \\
\hline Median $(Q 1, Q 3)$, years & $62.0(55.0,68.0)$ \\
\hline Min-Max, years & $23-84$ \\
\hline$<65$ years, $n(\%)$ & $319(64.2)$ \\
\hline$\geq 65$ years, $n(\%)$ & $178(35.8)$ \\
\hline \multicolumn{2}{|l|}{ Gender, $n(\%)$} \\
\hline Male & $255(51.3)$ \\
\hline Female & $242(48.7)$ \\
\hline \multicolumn{2}{|l|}{ Performance status (ECOG), $n$ (\%) } \\
\hline 0 & $51(10.3)$ \\
\hline 1 & $278(55.9)$ \\
\hline 2 & $154(31.0)$ \\
\hline 3 & $11(2.2)$ \\
\hline $\mathrm{N} / \mathrm{A}$ & $3(0.6)$ \\
\hline \multicolumn{2}{|l|}{ Tumor type, $n$ (\%) } \\
\hline Lung cancer & $98(19.7)$ \\
\hline Breast cancer & $39(7.8)$ \\
\hline Gynecological tumors & $57(11.5)$ \\
\hline Other solid tumors & $145(29.2)$ \\
\hline Hodgkin's disease & $6(1.2)$ \\
\hline Multiple myeloma & $56(11.3)$ \\
\hline Non-Hodgkin's lymphoma & $78(15.7)$ \\
\hline Other hematological malignancies & $18(3.6)$ \\
\hline \multicolumn{2}{|l|}{ Time since diagnosis } \\
\hline$N$ & 453 \\
\hline Mean (SD), days & $314.4(597.38)$ \\
\hline Median (Q1, Q3), days & $107.0(62.0,278.0)$ \\
\hline Min-Max, days & $3-6816$ \\
\hline Missing, $n$ & 44 \\
\hline Any comorbidities prior to enrollment, $n$ (\%) & $108(21.7)$ \\
\hline Any anticancer therapy prior to enrollment, $n(\%)$ & $44(8.9)$ \\
\hline Radiotherapy prior to enrollment, $n$ (\%) & $36(7.2)$ \\
\hline \multicolumn{2}{|c|}{$\begin{array}{l}\text { ECOG Eastern Cooperative Oncology Group, max maximum value, min mini- } \\
\text { mum value, } n \text { number of patients with the given parameter, } N \text { total number } \\
\text { of patients in the group/subgroup, } S D \text { standard deviation, } Q 1 \text { lower quartile, } \\
Q 3 \text { upper quartile }\end{array}$} \\
\hline
\end{tabular}

(Table 1). Most patients had not received any anemia treatments prior to study enrollment: 479 patients (96.4\%) had not received prior iron therapy and 473 $(95.2 \%)$ had not received any RBCT or full blood transfusions. Baseline laboratory assessments relevant to anemia are shown in Table S1 in the online supplemental material.

\section{Adherence to guidelines and hemoglobin evolution over time}

At initiation of darbepoetin alfa, 401 patients $(80.7 \%$, $95 \%$ CI $76.9,84.1$ ) had a $\mathrm{Hb}$ within the range of $\mathrm{Hb}$ 9-11g/dL recommended by the EORTC and the Romanian guidelines (primary endpoint; Table 2). These findings were independent of age category $(<65$ or $\geq 65$ years), gender, or chemotherapy type, but differed by certain tumor types (Table S2). The approved label recommends a $\mathrm{Hb} \leq 10 \mathrm{~g} / \mathrm{dL}$ at darbepoetin alfa initiation, which was adhered to by 269 patients $(54.1 \%$, 95\% CI 49.6, 58.6). For differences by age, gender, chemotherapy type, tumor type and FDOS, see Table S3.

$\mathrm{Hb}$ target achievement rates were provided for two different $\mathrm{Hb}$ levels as $\mathrm{Hb} \geq 10$ and $\mathrm{Hb}>11 \mathrm{~g} / \mathrm{dL}$. The proportions of patients with $\mathrm{Hb}<10 \mathrm{~g} / \mathrm{dL}$ at baseline achieving $\mathrm{Hb} \geq 10 \mathrm{~g} / \mathrm{dL}$ at weeks 6,9 , and 12 were $58.6 \% \quad(n=133 / 227), 60.0 \% \quad(n=137 / 226)$, and $56.5 \% \quad(n=126 / 223)$, respectively (Table 3$)$. After achieving $\geq 10 \mathrm{~g} / \mathrm{dL}$ for the first time, patients had a median (IQR) Hb of $10.96(10.19,11.93) \mathrm{g} / \mathrm{dL}$. The proportions of patients with $\mathrm{Hb} \leq 11 \mathrm{~g} / \mathrm{dL}$ at baseline achieving $\mathrm{Hb}>11 \mathrm{~g} / \mathrm{dL}$ at weeks 6 , 9, and 12 were $42.4 \%(n=188 / 443), 46.0 \% \quad(n=204 / 443)$, and $44.7 \%$ ( $n=197 / 441$; Table 3). After achieving $\mathrm{Hb}>11 \mathrm{~g} / \mathrm{dL}$ for the first time, patients had a median (IQR) $\mathrm{Hb}$ of $11.70(10.90,12.30) \mathrm{g} / \mathrm{dL}$. The median (IQR) time to achieve $\mathrm{Hb} \geq 10 \mathrm{~g} / \mathrm{dL}$ was 30.0 (21.0, 47.0) days; the median (IQR) time to achieve $\mathrm{Hb}>11 \mathrm{~g} / \mathrm{dL}$ was 34.5 (21.0, 57.0) days (Table S4). More patients with hematological malignancies than with solid tumors achieved $\mathrm{Hb}$ targets (Table 3 ). There was no significant difference by age category or gender. More patients receiving anthracyclines or regimens based on new monoclonal antibodies achieved these $\mathrm{Hb}$ target categories than other chemotherapy types (trend estimated for groups with a minimum of 20 patients at week 6). Fig. 2 shows $\mathrm{Hb}$ trajectories, overall and by tumor type. The shift categories from baseline to week 12 in Table 4 show the proportion of patients achieving a certain $\mathrm{Hb}$ value based on $\mathrm{Hb}$ at initiation. Of patients who were initiated on darbepoetin alfa at $\mathrm{Hb}<9 \mathrm{~g} / \mathrm{dL}, 26.8 \%$ achieved $\mathrm{Hb}>11 \mathrm{~g} / \mathrm{dL}$; in patients initiated at $\mathrm{Hb} 9-11 \mathrm{~g} / \mathrm{dL}, 48.1 \%$ achieved $\mathrm{Hb}>11 \mathrm{~g} / \mathrm{dL}$. 
Table $2 \mathrm{Hb}$ categories at baseline and RBCT requirements by $\mathrm{Hb}$ category and tumor type

\begin{tabular}{|c|c|c|c|c|}
\hline & \multirow{2}{*}{$\begin{array}{l}\text { Patients in category } \\
n(\%)\end{array}$} & \multicolumn{2}{|c|}{ Required transfusion } & \multirow{2}{*}{$\begin{array}{l}\text { Time to first transfusion } \\
\text { Median (IQR), days }\end{array}$} \\
\hline & & $n / N(\%)$ & $95 \% \mathrm{Cl}$ & \\
\hline Overall & $497(100.0)$ & 67 (13.5) & - & - \\
\hline $\mathrm{Hb}<9 \mathrm{~g} / \mathrm{dL}$ & 77 (15.5) & $16(20.8)$ & $12.4,31.5$ & $38.5(21.5,71.5)$ \\
\hline $\mathrm{Hb} 9-11 \mathrm{~g} / \mathrm{dL}$ & $401(80.7)$ & $50(12.5)$ & $9.4,16.1$ & $64.0(34.0,93.0)$ \\
\hline $\mathrm{Hb}>11 \mathrm{~g} / \mathrm{dL}$ & $19(3.8)$ & $1(5.3)$ & $0.1,26.0$ & $131.0(131.0,131.0)$ \\
\hline \multicolumn{5}{|c|}{ After 5 weeks of darbepoetin alfa treatment } \\
\hline Overall & $497(100.0)$ & $47 / 472(10.0)$ & $7.4,13.0$ & - \\
\hline Solid tumors & $339(100.0)$ & $29 / 320(9.1)$ & $6.2,12.8$ & - \\
\hline Hematological malignancies & $158(100.0)$ & 19/152 (11.8) & $7.2,18.1$ & - \\
\hline
\end{tabular}

Table 3 Proportion of patients achieving $\mathrm{Hb} \geq 10$ or $>11 \mathrm{~g} / \mathrm{dL}$ at specific timepoints

\begin{tabular}{|c|c|c|c|c|c|c|c|c|c|}
\hline \multirow[b]{2}{*}{ Covariates } & \multicolumn{3}{|c|}{ Overall } & \multicolumn{3}{|c|}{ Solid tumors } & \multicolumn{3}{|c|}{ Hematological malignancies } \\
\hline & $N$ & $n(\%)$ & $95 \% \mathrm{Cl}$ & $N$ & $n(\%)$ & $95 \% \mathrm{Cl}$ & $N$ & $n(\%)$ & $95 \% \mathrm{Cl}$ \\
\hline \multicolumn{10}{|c|}{ Patients achieving $H b \geq 10 \mathrm{~g} / \mathrm{dL}$} \\
\hline Week 6 & 227 & $133(58.6)$ & $51.9-65.1$ & 133 & $71(53.4)$ & $44.5-62.1$ & 94 & $62(66.0)$ & $55.5-75.4$ \\
\hline Week 9 & 226 & $137(60.6)$ & $53.9-67.0$ & 133 & $72(54.1)$ & $45.3-62.8$ & 93 & $65(69.9)$ & $59.5-79.0$ \\
\hline Week 12 & 223 & $126(56.5)$ & $49.7-63.1$ & 131 & $68(51.9)$ & $43.0-60.7$ & 92 & $58(63.0)$ & $52.3-72.9$ \\
\hline \multicolumn{10}{|c|}{ Patients achieving $\mathrm{Hb}>11 \mathrm{~g} / \mathrm{dL}$} \\
\hline Week 6 & 443 & $188(42.4)$ & $37.8-47.2$ & 315 & $130(41.3)$ & $35.8-46.9$ & 137 & $65(47.4)$ & $38.9-56.1$ \\
\hline Week 9 & 443 & $204(46.0)$ & $41.3-50.8$ & 315 & $135(42.9)$ & $37.3-48.5$ & 137 & $73(53.3)$ & $44.6-59.4$ \\
\hline Week 12 & 441 & $197(44.7)$ & $40.0-49.4$ & 314 & $135(43.0)$ & $37.4-48.7$ & 137 & $69(50.7)$ & $42.0-59.4$ \\
\hline
\end{tabular}

\section{Transfusion requirements}

Overall, $13.5 \%$ of patients $(n=67)$ had a total of 221 transfusions, 178 (80.5\%) of which were packed RBCTs and $43(19.5 \%)$ were full blood transfusions. Of 472 patients remaining on study after 5 weeks, 47 $(10.0 \%)$ had received their transfusion after a period of 5 weeks of darbepoetin alfa treatment. Of patients with a baseline $\mathrm{Hb}<9 \mathrm{~g} / \mathrm{dL}, 20.8 \%(n=16 / 77)$ required transfusions, as did $12.5 \%(n=50 / 401)$ with a baseline $\mathrm{Hb}$ of $9-11 \mathrm{~g} / \mathrm{dL}$, and $5.3 \%(n=1 / 19)$ with a baseline $\mathrm{Hb}>11 \mathrm{~g} / \mathrm{dL}$. The median time to first transfusion was 38.5 days in the baseline $\mathrm{Hb}$ category $<9 \mathrm{~g} / \mathrm{dL}, 64.0$ days in the Hb category 9-11 g/dL, and 131.0 in the $\mathrm{Hb}$ category $>11 \mathrm{~g} / \mathrm{dL}$ (Table 2 ). Per transfusion event, $\leq 2$ units were administered in 218 (98.6\%) events and $>2$ units in 3 (1.4\%) events.

\section{Chemotherapy delivery}

According to the described definition, $30.0 \%$ of patients $(n=149,95 \%$ CI $26.0,34.2)$ received FDOS. There was, however, some difference between chemotherapy and tumor types as detailed in Table S5.

\section{Exposure to darbepoetin alfa}

The median (IQR) cumulative administered darbepoetin alfa dose was 1800.0 (1000.0, 2500.0) $\mu$ g (range 500-8000), with a median (IQR) duration of exposure of $84.0(53.0,117.0)$ days (range 7-352).

\section{Safety}

One non-serious ADR (vena cava thrombosis) and no serious ADRs were reported.

\section{Discussion}

Recommendations for ESA initiation vary between international guidelines, with the EORTC guidelines recommending a $\mathrm{Hb}$ range of 9-11 g/dL [4] and the ESMO guidelines recommending $\mathrm{Hb} \leq 10 \mathrm{~g} / \mathrm{dL}$ [5]. Romanian health authorities recommended the initiation of ESA therapy in patients with a $\mathrm{Hb}$ range of $9-11 \mathrm{~g} / \mathrm{dL}$ and later on in patients with $\mathrm{Hb}$ level between $8-10 \mathrm{~g} / \mathrm{dL}$ [7]. The APPLY study (A Prospective Aranesp ${ }^{\circledR}$ Observational Study in Patients with Chemotherapy-Induced Anemia) found that $80.7 \%$ of 


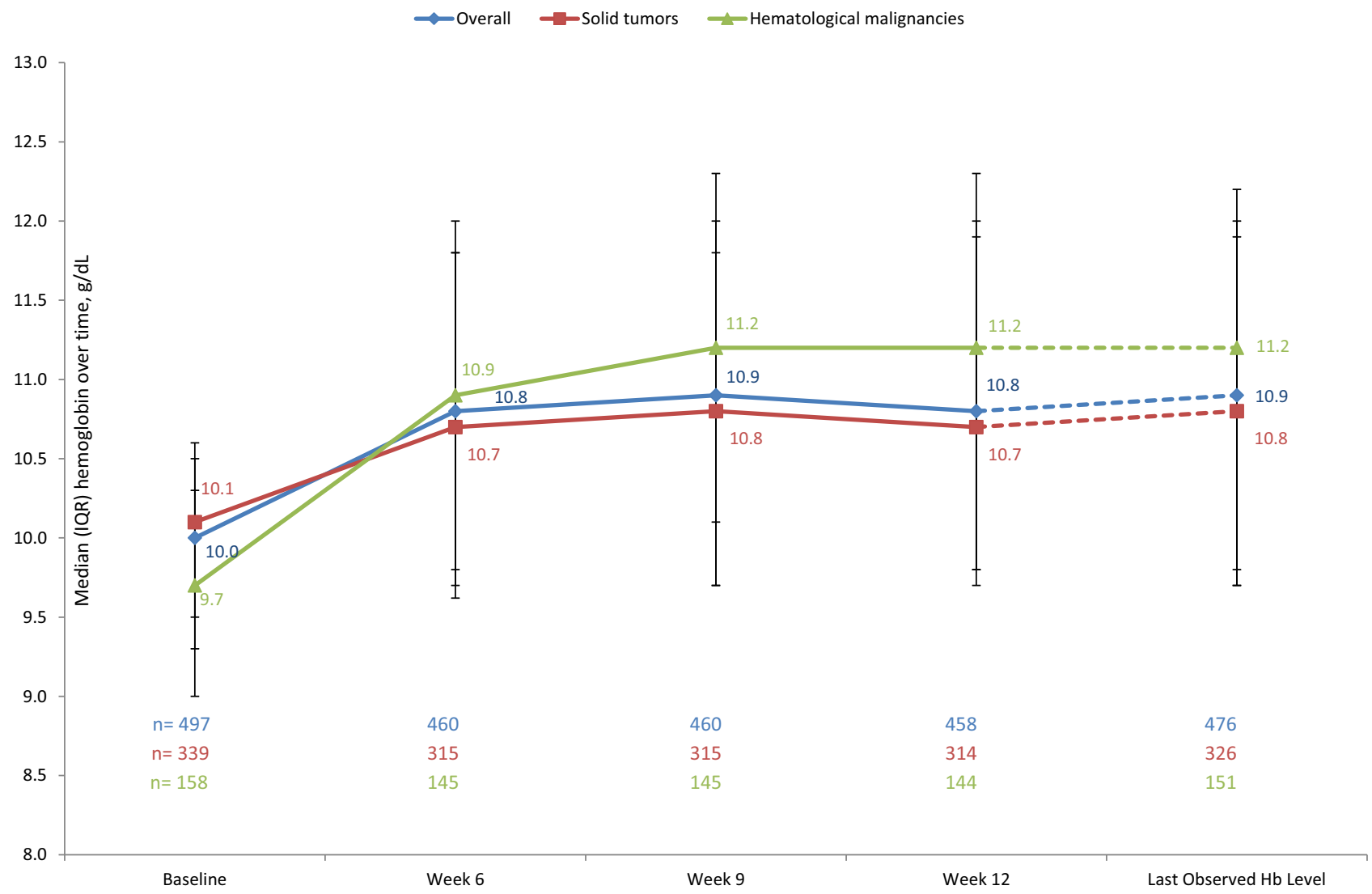

Fig. 2 Median (IQR) hemoglobin over time, overall and by tumor type. The timepoint of last observed $\mathrm{Hb}$ is different for each patient; the dotted line shows that last observed $\mathrm{Hb}$

patients were initiated on darbepoetin alfa treatment within the $\mathrm{Hb}$ range of $9-11 \mathrm{~g} / \mathrm{dL}$, indicating that treatment of patients with chemotherapy-induced anemia is generally congruent with the Romanian recommendations. The darbepoetin alfa label recommendations of $\mathrm{Hb} \leq 10 \mathrm{~g} / \mathrm{dL}$ at initiation were adhered to by $54.1 \%$.

There is only a limited number of studies reporting $\mathrm{Hb}$ strata at initiation of ESAs generally, and of darbepoetin alfa in particular, and reported strata vary between studies because of the abovementioned differences in recommendations and a label change in 2008, where the $\mathrm{Hb}$ level recommended for initiation of ESAs as changed from $\mathrm{Hb}$ $9-11 \mathrm{~g} / \mathrm{dL}$ to $\leq 10 \mathrm{~g} / \mathrm{dL}$. Of noninterventional studies, the international IMPACT study (A Retrospective and Prospective Observational Study Reviewing Supportive Care Management of NHL Patients Treated With CHOP-14 or 21 Chemotherapy With or Without Rituximab) was conducted in 14 European countries and Australia [8]. In the subanalysis of patients with non-Hodgkin lymphoma receiving cyclophosphamide-doxorubicin-vincristine-prednisolone (CHOP) \pm rituximab, $67 \%$ of patients had $\mathrm{Hb}$ concentrations of $9-11 \mathrm{~g} / \mathrm{dL}$ at the time of initiation of darbepoetin alfa [8]. The observational, noninterventional 'A Prospective Data Audit from Patients was not necessarily measured after week 12 . IQR interquartile range, $\mathrm{Hb}$ hemoglobin

Treated with Aranesp Due to Chemotherapy Induced Anaemia' (APRIORI) study conducted in 6408 patients in Poland, The Czech Republic, Slovakia, Slovenia, Hungary, and Russia assessed adherence to treatment guidelines for the use of darbepoetin in patients with chemotherapy-induced anemia, i.e., adherence to product labeling recommendations before and after changes were made to the darbepoetin alfa SmPC in 2008. The study found that $56.4 \%$ of patients were initiated on darbepoetin alfa at $\mathrm{a} \mathrm{Hb}$ in the range of 9-11 g/dL range dL before label change versus $90.0 \%$ of patients initiating darbepoetin alfa at a $\mathrm{Hb} \leq 10 \mathrm{~g} / \mathrm{dL}$ after label change [9]. Compared to these studies, in APPLY substantially more patients had darbepoetin alfa initiated in the $\mathrm{Hb}$ range of $9-11 \mathrm{~g} / \mathrm{dL}$, which is in line with Romanian health authority guidance and EORTC guidelines.

In APPLY, which to our knowledge is the largest observational with darbepoetin alfa in Romania, symptomatic anemia was successfully corrected with a median $\mathrm{Hb}$ increase of $0.90 \mathrm{~g} / \mathrm{dL}$ from a median $\mathrm{Hb}$ of $10.00 \mathrm{~g} / \mathrm{dL}$ at baseline to $10.80 \mathrm{~g} / \mathrm{dL}$ at week 12 . Change from baseline was higher in patients with hematological malignancies than in those with solid tumors. The APPLY study descriptively analyzed $\mathrm{Hb}$ target achievement in two ways: achievement of $\mathrm{Hb}>10 \mathrm{~g} / \mathrm{dL}$ and achievement of $\mathrm{Hb}>11 \mathrm{~g} / \mathrm{dL}$. Inter- 
Table 4 Shift from baseline in $\mathrm{Hb}$ levels at week 12 (proportions of patients)

\begin{tabular}{|c|c|c|c|c|}
\hline \multirow[t]{2}{*}{ Hb level at week 12} & \multicolumn{4}{|c|}{$\mathrm{Hb}$ level at Baseline (in \%) } \\
\hline & $<9 \mathrm{~g} / \mathrm{dL}$ & $9-11 \mathrm{~g} / \mathrm{dL}$ & $>11 \mathrm{~g} / \mathrm{dL}$ & Total \\
\hline$<10 \mathrm{~g} / \mathrm{dL}$ & 50.7 & 28.9 & 5.9 & 31.4 \\
\hline$\geq 10 \mathrm{~g} / \mathrm{dL}$ & 49.3 & 71.1 & 94.1 & 68.6 \\
\hline$\leq 11 \mathrm{~g} / \mathrm{dL}$ & 73.2 & 51.9 & 29.4 & 54.4 \\
\hline$>11 \mathrm{~g} / \mathrm{dL}$ & 26.8 & 48.1 & 70.6 & 45.6 \\
\hline
\end{tabular}

estingly, if anemia treatment was initiated at a baseline $\mathrm{Hb}$ within the recommended range of $9-11 \mathrm{~g} / \mathrm{dL}$ substantially more patients achieved either of these targets compared to patients who were initiated with darbepoetin alfa at a $\mathrm{Hb}$ value $<9 \mathrm{~g} / \mathrm{dL}$. The median time to achieve $\mathrm{Hb}>10 \mathrm{~g} / \mathrm{dL}$ or $\mathrm{Hb}>11 \mathrm{~g} / \mathrm{dL}$ was 30.0 days and 34.5 days, respectively. Of note, $\mathrm{Hb}$ values within 28 days after RBCT or full blood transfusion were excluded from the analysis; therefore, transfusions did not alter the results. This is in line with the IMPACT study, where $52 \%$ of patients with a baseline $\mathrm{Hb}<10 \mathrm{~g} / \mathrm{dL}$ achieved a $\mathrm{Hb} \geq 10 \mathrm{~g} / \mathrm{dL}$ after 5 weeks of treatment with darbepoetin alfa, and $44 \%$ of patients with $\mathrm{Hb}<11 \mathrm{~g} / \mathrm{dL}$ achieved $\mathrm{Hb} \geq 11 \mathrm{~g} / \mathrm{dL}$ after the same period [8]. In the European observational study 'Current Practice of Aranesp in the Management of Hemoglobin Levels: an Observational International Cancer Evaluation' (CHOICE), conducted in 11 European countries in 1900 patients with solid tumors, $57 \%$ of enrolled patients had a baseline $\mathrm{Hb}$ level $<10 \mathrm{~g} / \mathrm{dL}$ and $91 \%$ had $<11 \mathrm{~g} / \mathrm{dL}$. At week $9,54 \%$ of patients still in the study and with available $\mathrm{Hb}$ values achieved the predefined $\mathrm{Hb}$ target value of $10-12 \mathrm{~g} / \mathrm{dL}$ $[10,11]$. Taken together the findings of the present study are in line with other observational studies conducted in Europe.

Transfusion requirements differed by $\mathrm{Hb}$ category at baseline. Patients who were initiated with darbepoetin alfa at a $\mathrm{Hb}$ within the recommended range of 9-11 g/dL requiring fewer transfusions compared with patients initiated below the recommended range. $\mathrm{Pa}$ tients treated according to the recommendations also had a longer time to first transfusions than patients initiated at a lower than recommended $\mathrm{Hb}$. A study estimating the incidence of at least one transfusion by baseline $\mathrm{Hb}$ ranges found that transfusion rates were highest in the $<9 \mathrm{~g} / \mathrm{dL}$ baseline $\mathrm{Hb}$ group in all 4 -week time periods examined [12]. Deger et al. showed similar trends, reporting an association between $\mathrm{Hb}$ level at initiation of darbepoetin alfa, transfusion requirements and associated costs for transfusion [13].

This study has several limitations. The primary risk of bias in observational studies is that of selection bias, wherein the sampled patient population may not be representative of the overall patient population in the region. Also, only patients treated with darbepoetin alfa were included. The decision to enroll a given patient into the study was taken after the physician had decided on the individual treatment approach for a given patient. It is unclear whether this may have introduced a certain selection bias, since longer-acting ESAs may be selected for different types of patients than shorter-acting ESAs. Confounding bias is a further bias inherent to this type of study. There are many confounding factors that can affect the $\mathrm{Hb}$ level over time, which do not necessarily reflect the efficacy of the treatment, such as the intensity of chemotherapy, iron supplementation or darbepoetin alfa dose adjustments or withholdings in response to $\mathrm{Hb}$ evolution. The national Romanian protocol for treatment of chemotherapy-induced anemia with ESAs recommends treatment of symptomatic anemia with a $\mathrm{Hb}$ in the range of $9-11 \mathrm{~g} / \mathrm{dL}$ with a treatment $\mathrm{Hb}$ target of above $11 \mathrm{~g} / \mathrm{dL}$. Once the target $\mathrm{Hb}$ is reached, it is recommended to individualize treatment to maintain $\mathrm{Hb}$ with a minimum of treatment. However, the local prescription protocol in Bucharest changed in 2013, approximately one year after the study start, and allowed initiation of ESAs only in patients with a $\mathrm{Hb}$ in the range of $8-10 \mathrm{~g} / \mathrm{dL}$. Of the 35 participating centers, eight were in Bucharest, contributing a total of 118 patients (24\% of the 497 patients in the FAS). Of the total study population, 263 patients $(52.9 \%)$ were enrolled at a $\mathrm{Hb}$ of $8-10 \mathrm{~g} / \mathrm{dL}$ and 77 patients (15.5\%) at $\mathrm{Hb}<9 \mathrm{~g} / \mathrm{dL}$. The $\mathrm{Hb}$ shift table shown in Table 4 shows that fewer patients with $\mathrm{Hb}<9 \mathrm{~g} / \mathrm{dL}$ at baseline achieved $\mathrm{Hb}>10 \mathrm{~g} / \mathrm{dL}$ or $>11 \mathrm{~g} / \mathrm{dL}$, as was defined as the target $\mathrm{Hb}$ in the secondary endpoints. This finding suggests that initiating ESAs rather earlier than later within the recommended range of $\mathrm{Hb} 9-11 \mathrm{~g} / \mathrm{dL}$ may improve target achievement. There are several other factors potentially confounding the results of $\mathrm{Hb}$ evolution and target achievement over time. $\mathrm{Hb}$ values may vary strongly by tumor type and type of chemotherapy administered, as well as by comorbidities and concomitant medications. The potential influence of tumor type and chemotherapy type has been addressed in a logistic regression model and data are provided in the online supplement. Concomitant medications and comorbidities have, however, not been addressed in a similar way in a logistic regression model.

In order to minimize risk of selection bias, the selection of study sites encompassed sites from every major region of Romania that are capable of satisfying the selection criteria. Every attempt was made to include sites that are representative of patients across the country and representative of the types of disease 
(both solid and hematological tumor types) prevalent in the region. Efforts were made to ensure that each site contributed an appropriate number of patients to the overall analysis by specifying minimum and maximum total enrollment per site. This observational study was monitored (full monitoring in a representative sample, monitoring of key data such as provision of informed consent, eligibility criteria, safety reports, etc. in all patients) to minimize information bias.

While the darbepoetin alfa label mentions several types of adverse reactions, such as immune system disorder (hypersensitivity), cardiac and vascular (hypertension, thromboembolic events including pulmonary embolism), skin and subcutaneous tissue disorders (rash/erythema), and other administration site disorders (injection site pain), we found a low rate of reported adverse events, despite the physicians' obligation to report, either to Romanian National Drug Agency or to the study sponsor.

\section{Conclusions}

In this single-arm, prospective, longitudinal, multicenter observational study, approximately $80 \%$ of patients with symptomatic chemotherapy-induced anemia had a $\mathrm{Hb}$ in the range of $9-11 \mathrm{~g} / \mathrm{dL}$ prior to antianemic treatment with darbepoetin alfa. During treatment with darbepoetin alfa pre-existing anemia improved substantially, with patients experiencing a median increase in $\mathrm{Hb}$ of $0.9 \mathrm{~g} / \mathrm{dL}$ between baseline and week $12 ; 57 \%$ of patients with $\mathrm{Hb}<10 \mathrm{~g} / \mathrm{dL}$ at baseline achieved $\mathrm{Hb} \geq 10 \mathrm{~g} / \mathrm{dL}$ and $46 \%$ of patients with $\mathrm{Hb} \leq 11 \mathrm{~g} / \mathrm{dL}$ at baseline achieved $\mathrm{Hb}>11 \mathrm{~g} / \mathrm{dL}$ at week 12. The results of this study do not alter the currently known benefit-risk balance of darbepoetin alfa.

Acknowledgements The authors would like to acknowledge all APPLY investigators as well as the contribution of Martina Altenriederer and Silke Gruber, Amgen $\mathrm{GmbH}$, for study coordination. Margit Hemetsberger, Hemetsberger medical services, Vienna, Austria, provided medical writing. Irina Kotenko, Yuliya Bagatskaya, Leonid Zeitlin, Dmitry Kalinin, Aleksandr Roshchupkin, and Evgeniy Pavlenko of Quartesian, Kharkov, Ukraine, provided the statistical analysis. This study, including statistical analysis and medical writing, was funded by Amgen Romania.

Conflict of interest N.M. Berbec has received consulting fees from Amgen. D.L. Stanculeanu has received consulting fees from Amgen, Janssen, and Roche and is a member of the speakers bureau of Amgen, Roche, Merck, Novartis, Astellas, Janssen, Bristol-Myers Squibb, and Astra-Zeneca. N.S. Badelita received consulting fees from Amgen and is a member of the speakers bureau of Amgen. A. Colita received speakers fees from Amgen. C. Neacsu and A. Iordan are employees of Amgen and hold Amgen stock. M. Vasilica and D.I. Popovici declare that they have no competing interests.

Open Access This article is distributed under the terms of the Creative Commons Attribution 4.0 International License (http://creativecommons.org/licenses/by/4.0/), which per- mits unrestricted use, distribution, and reproduction in any medium, provided you give appropriate credit to the original author(s) and the source, provide a link to the Creative Commons license, and indicate if changes were made.

\section{References}

1. Groopman JE, Itri LM. Chemotherapy-induced anemia in adults: incidence and treatment. J Natl Cancer Inst. 1999;91(19):1616-34.

2. Ludwig H, Fritz E. Anemia in cancer patients. Semin Oncol. 1998;25(3 Suppl7):2-6.

3. Cella D, Lai JS, Chang CH, Peterman A, Slavin M. Fatigue in cancer patients compared with fatiguein the general United States population. Cancer. 2002;94(2):528-38.

4. Aapro MS, Link H. September 2007 update on EORTC guidelines and anemia management with erythropoiesisstimulating agents. Oncologist. 2008;13(Suppl3):33-6.

5. Schrijvers D, De Samblanx H, Roila F, Group EGW. Erythropoiesis-stimulating agents in the treatment of anaemia in cancer patients: ESMO clinical practice guidelines for use. Ann Oncol. 2010;21(Suppl5):v244-v7.

6. European Medicines Agency. Aranesp summary of product characteristics. European Medicines Agency. 2015. http://www.ema.europa.eu/ema/index.jsp?curl=pages/ medicines/human/medicines/000332/human_med_000 651.jsp\&mid=WC0b01ac058001d124. Accessed 27 Mar 2017.

7. Romanian Health Ministry. Romanian-protocol 2008, Health Minister Order 1301/500 from 11 july 2008. 2008.

8. Pettengell R, Silvestre AS, Schwenkglenks M, Rossi FG, Duehrsen U, Verhoef G, Lugtenburg PJ, Wheeler T, Pujol B, Haioun C. Darbepoetin alfa administration in patients with non-Hodgkin lymphoma and chemotherapy-induced anemia receiving $( \pm \mathrm{R})$ CHOP. Hematology. 2013;18(1):26-9.

9. Boguradzki P, Boér K, Cipková A, Wojciechowska-Lampka E, Schützová M, Ocvirk J, Tóth E. Oncology Pro. A prospective data audit of the management of chemotherapyinduced anemia with darbepoetin alfa 6 the APRIORI study. 2012. http://oncologypro.esmo.org/MeetingResources/ESMO-2012/A-prospective-data-audit- ofthe-management- of-chemotherapy-induced-anemiawith-darbepoetin-alfa-6-the-APRIORI-study. Accessed 27 Oct 2016

10. Van Belle S, Karanikiotis C, Labourey JL, Galid A, Wheeler $\mathrm{T}$, Pujol B. Current practice of darbepoetin alfa in the management of haemoglobin levels in cancer patients undergoing chemotherapy-data from the CHOICE study. Curr Med Res Opin. 2011;27(5):987-94.

11. Van Belle S, Urbanski K, Orfeuvre H, Foucher P, Wheeler T, Pujol B. Darbepoetin alfa dosing weekly and every three weeks in cancer patients with chemotherapy-induced anaemia-efficacy data from the CHOICEstudy. Ann Oncol. 2010;21(S8):viii-386.

12. Canon JL, Vansteenkiste J, Hedenus M, Gascon P, Bokemeyer C, Ludwig H, Vermorken J, Legg J, Pujol B, Bridges $\mathrm{K}$. Transfusion risk in cancer patients with chemotherapyinduced anemia when initiating darbepoetin alfa therapy at a baseline hemoglobin level of $<9 \mathrm{~g} / \mathrm{dL}$ versus 9 to $<10 \mathrm{~g} / \mathrm{dL}$ versus $\geq 10 \mathrm{~g} / \mathrm{dL}$ : an exploratory analysis of a phase 3 trial. Med Oncol. 2012;29(3):2291-9.

13. Deger M, Eisterer W, Kutikova L, Salek S. Hemoglobin level at initiation of darbepoetin alfa: impact on need for transfusion and associated costs in chemotherapyinduced anemia treatment in Europe. SupportCareCancer. 2013;21(2):485-93. 